\title{
Detection of integrin-linked kinase in the serum of patients with malignant pleural mesothelioma
}

\author{
Stefan B. Watzka, MD, ${ }^{\text {a,b }}$ Florian Posch, Cand.Med., ${ }^{\text {b,c }}$ Harvey I. Pass, MD, ${ }^{\mathrm{d}}$ Margaret Huflejt, PhD, ${ }^{\mathrm{d}}$ \\ David Bernhard, $\mathrm{PhD},{ }^{\mathrm{c}}$ Gregory E. Hannigan, $\mathrm{PhD},{ }^{\mathrm{e}}$ and Michael R. Müller, MD, $\mathrm{PhD}^{\mathrm{a}, \mathrm{b}}$
}

Objective: Integrin-linked kinase, which is relevant to neoplastic transformation, is highly expressed in malignant pleural mesothelioma. Recently, detection of integrin-linked kinase in serum of patients with ovarian cancer has been reported. This study asks whether integrin-linked kinase can also be detected in serum of patients with malignant pleural mesothelioma and whether serum level has diagnostic or prognostic relevance for that disease.

\begin{abstract}
Methods: A sandwich enzyme-linked immunosorbent assay was designed to detect integrin-linked kinase and applied to serum samples from 46 patients with malignant pleural mesothelioma, 98 patients with other malignant chest disease, and 23 patients with benign chest disease. Integrin-linked kinase serum concentration and clinical data were correlated statistically.
\end{abstract}

Results: Median serum integrin-linked kinase concentration was significantly higher in malignant pleural mesothelioma $(8.89 \mathrm{ng} / \mathrm{mL})$ than in other malignant chest disease $(0.66 \mathrm{ng} / \mathrm{mL})$ or benign chest disease $(0.78 \mathrm{ng} / \mathrm{mL}$, $P<.001)$. There was no relevant correlation of serum integrin-linked kinase with cell lysis parameters $\left(R^{2}<0.1\right)$. Serum integrin-linked kinase concentration greater than $2.48 \mathrm{ng} / \mathrm{mL}$ had diagnostic sensitivity of $80 \%$, specificity of $95 \%$, positive predictive value of $85.7 \%$, negative predictive value of $92.7 \%$, and overall accuracy of $91 \%$ for distinction between malignant pleural mesothelioma and other diseases. Serum integrin-linked kinase concentration in malignant pleural mesothelioma was independent of histologic subtype or asbestos exposure. There was no statistically significant impact of serum integrin-linked kinase concentration on prognosis.

Conclusions: Integrin-linked kinase can be detected in serum of patients with malignant pleural mesothelioma and may be a diagnostic marker for the disease. (J Thorac Cardiovasc Surg 2011;142:384-9)

Malignant pleural mesothelioma (MPM) is a tumor derived from the mesodermal pleural layers that is mostly associated with asbestos exposure. Clinically, MPM is characterized by aggressive local spread, few or nonspecific symptoms at early stages, low response to cytostatic drugs ${ }^{1}$ and radiation, and a particularly poor prognosis. ${ }^{2}$ Despite intense multimodality therapy efforts, ${ }^{3-5}$ outcomes have not considerably improved, because most patients are seen with already advanced disease. Early detection by reliable biomarkers may thus be a valuable strategy to improve outcome for patients with MPM.

From the Division of Thoracic Surgery ${ }^{\mathrm{a}}$ and the Karl Landsteiner Institute for Thoracic Oncology, ${ }^{\mathrm{b}}$ Otto Wagner Hospital, Vienna, Austria; the Cardiac Surgery Research Laboratory, ${ }^{\mathrm{c}}$ Surgical Research Laboratories, Medical University of Vienna, Vienna, Austria; the Division of Thoracic Surgery and Thoracic Oncology, ${ }^{\mathrm{d}}$ NYU Langone Medical Center and Cancer Center, New York, NY; and the Centre for Cancer Research, ${ }^{\mathrm{e}}$ Monash Institute of Medical Research, Monash University, Melbourne, Australia.

Specimen collection for the mesotheliomas at the NYU Langone Medical Center was supported by a National Cancer Institute Early Detection Research Network Grant to H.I.P.

Disclosures: Authors have nothing to disclose with regard to commercial support. Received for publication Dec 22, 2010; revisions received Feb 28, 2011; accepted for publication April 26, 2011; available ahead of print May 27, 2011.

Address for reprints: Stefan B. Watzka, MD, Division of Thoracic Surgery, Karl Landsteiner Institute for Thoracic Oncology, Otto Wagner Hospital, Sanatoriumstraße 2; 1140 Vienna, Austria (E-mail: s.watzka@utanet.at).

$0022-5223 / \$ 36.00$

Copyright (c) 2011 by The American Association for Thoracic Surgery doi:10.1016/j.jtcvs.2011.04.034
Chronic inflammation of the pleura is the basic pathogenetic principle of MPM. $^{6}$ One molecule that has been implicated with chronic inflammatory processes is integrin-linked kinase (ILK), an intracellular serine/threonine kinase that links $\beta$-integrins to the cytoskeleton. ${ }^{7}$ In addition to being required for inflammatory responses, ${ }^{8}$ ILK can (when overexpressed) induce an epithelialmesenchymal transition and a tumorigenic phenotype in epithelial cells. ${ }^{9}$ Conversely, inhibition of ILK exerts antineoplastic effects. ${ }^{10}$ We first showed that ILK is highly expressed in $90 \%$ of MPM samples, regardless of the histologic subtype, whereas healthy pleural and lung tissue does not express ILK at all. ${ }^{11,12}$ Support for a specific role of ILK in MPM biology comes from a recent study that shows that increased expression of kindlin-2 (an integrininteracting focal adhesion protein of the kindlin family) at the MPM invasion front coincides morphologically and functionally with ILK, thus pointing to a putative role of ILK and its associated protein kindlin-2 in the progression of MPM. ${ }^{13}$

In 2004, Ahmed and colleagues ${ }^{14}$ reported the detection of ILK in the serum of 30 ovarian cancer patients as well as 6 healthy subjects. Because ILK levels rose with tumor stage and were on average 6-fold higher in the cancer group, they proposed serum ILK-concentration as a novel marker for ovarian carcinoma. Despite their promising results, no research dealing with serum ILK in other cancer types has 


\section{Abbreviations and Acronyms \\ $\mathrm{BCD}=$ benign chest disease \\ ILK = integrin-linked kinase \\ MCD = malignant chest disease other than malignant pleural mesothelioma \\ MPM = malignant pleural mesothelioma \\ $\mathrm{SMRP}=$ soluble mesothelin-related peptide}

followed their investigations. Supported by our previous results, as well as those of Ahmed and colleagues, ${ }^{14}$ we hypothesized that serum ILK concentration can be used as a marker for MPM. To test this hypothesis, this study was designed to determine (1) whether ILK is present in the serum of patients with MPM, (2) whether there are concentration differences between MPM and control groups consisting of patients with other malignant chest disease (MCD) and patients with benign chest disease (BCD), (3) whether any such differences are strong enough to establish the parameter of serum ILK as a diagnostic marker for MPM, and (4) whether the serum ILK concentration predicts prognosis in patients with MPM.

\section{MATERIALS AND METHODS \\ Patient and Sample Recruitment}

The study was approved by the institutional review board of the Otto Wagner Hospital, Vienna, Austria. All participating patients had signed written, informed consent before donating a vial of venous blood for storage in the thoracic surgical tissue bank (either at NYU Langone Medical Center in the United States or at the Otto Wagner Hospital in Vienna) and for subsequent prognostic marker isolation. From this thoracic surgical tissue bank, frozen serum samples of 46 patients with MPM were retrieved (study group); all these blood samples were drawn at the time of surgery, before the incision. The control group consisted of frozen serum samples of 98 treatment-naive patients with MCD, and 23 treatment-naive patients with BCD (Table 1). The frozen serum samples of the study and the control groups were transferred to the Cardiac Surgery Research Laboratories, Medical University of Vienna, Vienna, Austria, for subsequent serum ILK analysis. The laboratory personnel responsible for the serum ILK analysis were blinded to the identities and to the clinical conditions of the participating patients.

\section{Detection of Serum ILK}

Ahmed and colleagues ${ }^{14}$ analyzed serum samples by Western blotting, and we also used this technique for pilot investigations in our first patients. Because of that procedure's limited ability to quantify the exact amount of protein detected, we chose to design a novel sandwich enzyme-linked immunosorbent assay. Standard 96-well microtiter plates (Nunc Immuno Plates Maxi Sorp C96, 430341; Nunc GmbH \& Co KG, Langenselbold, Germany) were coated with a $2-\mu \mathrm{g} / \mathrm{mL}$ solution of a capture antibody (Sigma-Aldrich I 783 mouse/anti-ILK/monoclonal; Sigma-Aldrich Handels Gmbh, Vienna, Austria), diluted in Dulbecco phosphate-buffered saline solution (Gibco 14040091; Invitrogen Corporation, Carlsbad, Calif) and incubated overnight at $4{ }^{\circ} \mathrm{C}$. After 3 washings with Dulbecco phosphate-buffered saline solution, a $2 \%$ solution of bovine serum albumin (Sigma-Aldrich I 7030) diluted in Dulbecco phosphate-buffered saline solution was filled into the wells to prevent nonspecific binding reactions. Af- ter an incubation period of 1 hour at room temperature and no washing, native serum specimens and an ILK-standard curve, consisting of 7 declining concentrations of recombinant ILK (originating from G.E.H.'s laboratory in Melbourne, Australia) diluted in fetal calf serum $(100 \mathrm{pg} / \mathrm{mL}, 10 \mathrm{pg} /$ $\mathrm{mL}, 1 \mathrm{pg} / \mathrm{mL}, 100 \mathrm{ng} / \mathrm{mL}, 10 \mathrm{ng} / \mathrm{mL}, 1 \mathrm{ng} / \mathrm{mL}, 0 \mathrm{ng} / \mathrm{mL}$ ) were incubated for 1 hour. Next, we washed the plate 3 times, added the polyclonal detecting antibody (Sigma-Aldrich I 1907, rabbit/anti-ILK, concentration $2 \mu \mathrm{g} /$ $\mathrm{mL}$ ) diluted in a $2 \%$ solution of bovine serum albumin, incubated the plate for 1 hour at room temperature, and washed it 3 times. The same step was done subsequently for the conjugated antibody (concentration $2 \mu \mathrm{g} / \mathrm{mL}$ ) diluted in a $2 \%$ solution of bovine serum albumin. Finally, we filled each well with $100 \mu \mathrm{L}$ of the tetramethylbenzidine-solution (Pierce 34021; Thermo Fisher Scientific Inc, Rockford, Ill) and stopped the colorimetric reaction with a $2-\mathrm{mol} / \mathrm{L}$ solution of sulfuric acid. Absorbance measurement was performed on a multilabel plate reader (Victor3 model 1420; PerkinElmer Inc, Waltham, Mass) at a wavelength of $450 \mathrm{~nm}$, followed by calculation of serum ILK concentration according to a previously established standard curve model. ILK enzyme-linked immunosorbent assay was performed in 2 separate runs for every sample, and additionally in 2 wells per run. The ILK-specific enzyme-linked immunosorbent assay had an intraclass correlation coefficient of 0.997 (95\% confidence interval, 0.992-1.00) in its standard curve, and therefore the results were considered to be extremely reliable.

\section{Clinical Data Gathering}

The following clinical and laboratory parameters were recorded: age, sex, smoking history, diagnosis, histologic subtype of MPM or MCD, asbestos exposure for patients with MPM, combined stage of MPM or MCD, surgical procedures for MPM, disease progression in MPM, survival status of patients with MPM, survival time with MPM, and the cell lysis parameters creatine kinase, lactate dehydrogenase, aspartate aminotransferase, and alanine aminotransferase (from 120 participating patients, including 4 patients with MPM). For determination of smoking history, asbestos exposure, and survival status, the patients were personally contacted and interviewed; all other parameters were retrieved from the clinical charts. All patients with MPM were followed up with computed tomographic scans every 3 months until death and were also routinely seen by the surgeons. Progression was documented either by changes in computed tomographic findings, by new biopsy of growing areas, or by aspiration cytologic sampling of newly developing ascites. Survival was scored from the day of the operation until death in months, and all data are accurate to November 2010. Median potential follow-up for the living patients was $45 \pm 5$ months (range, $32-83$ months). The data were censored at the time of last follow-up.

Patients with BCD were significantly younger than patients with MPM or MCD $(P<.001)$; however, there was no significant difference in age between those with MPM and those with $\operatorname{MCD}(P=.42)$. There were no significant differences in sex distribution $(P=.32)$ and smoking history $(P=.11)$ between the study group and the control groups (Table 1). After plotting of all serum ILK concentrations, 1 MPM sample was excluded from further analysis because of an extremely high and outlying serum ILK concentration (10 times higher than the highest concentration of the remaining samples), which raised the suspicion of a technical error. A sample comprising a total of 166 patients was further thus analyzed by statistical means.

\section{Statistical Analysis}

Data were analyzed with the SPSS statistical software package (SPSS Windows, version 17.0; SPSS Inc, an IBM Company, Chicago, Ill). Metric data, such as survival time or ILK, are expressed as mean \pm SD when normally distributed. Skewed metric data are expressed with mean, median, interquartile range, minimum value, and maximum value. Nominal data are presented as absolute frequencies and percentages. Correlations between nominal data were assessed with cross-tabulation and the $\chi^{2}$ test, 
TABLE 1. Demographic characteristics of study and control groups

\begin{tabular}{|c|c|c|c|}
\hline & $\begin{array}{c}\text { MPM } \\
(n=45)\end{array}$ & $\begin{array}{c}\text { MCD } \\
(\mathbf{n}=\mathbf{9 8})\end{array}$ & $\begin{array}{c}\text { BCD } \\
(\mathbf{n}=\mathbf{2 3})^{*}\end{array}$ \\
\hline Age $\dagger(y$, mean $\pm \mathrm{SD})$ & $65.5 \pm 10.5$ & $62 \pm 13.2$ & $51 \pm 15.7$ \\
\hline \multicolumn{4}{|l|}{$\operatorname{Sex} \ddagger$} \\
\hline Male & $73.9 \%$ & $64.3 \%$ & $56.5 \%$ \\
\hline Female & $26.1 \%$ & $35.7 \%$ & $43.5 \%$ \\
\hline \multicolumn{4}{|l|}{ Smoking history§ } \\
\hline Never smoked & $60 \%$ & $38.8 \%$ & $47.8 \%$ \\
\hline Smoker & $40 \%$ & $61.2 \%$ & $52.2 \%$ \\
\hline \multicolumn{4}{|l|}{ Asbestos exposure } \\
\hline No & $26.7 \%$ & & \\
\hline Yes & $73.3 \%$ & & \\
\hline \multicolumn{4}{|l|}{ Histologic subtype of MPM } \\
\hline Epitheloid & $66.7 \%$ & & \\
\hline Other subtype & $33.3 \%$ & & \\
\hline \multicolumn{4}{|l|}{ Histologic subtype of MCD } \\
\hline Squamous NSCLC & & $21.4 \%$ & \\
\hline Nonsquamous NSCLC & & $41.8 \%$ & \\
\hline Miscellaneous MCD\| & & $36.8 \%$ & \\
\hline \multicolumn{4}{|l|}{ Stage } \\
\hline Stage I and II & $40 \%$ & $45.9 \%$ & \\
\hline Stages III and IV & $60 \%$ & $54.1 \%$ & \\
\hline \multicolumn{4}{|l|}{ Surgical procedures for MPM } \\
\hline Extrapleural pneumonectomy & $62.2 \%$ & & \\
\hline Pleurectomy, decortication & $35.6 \%$ & & \\
\hline Other & $2.2 \%$ & & \\
\hline
\end{tabular}

All data represent percentages of patients unless otherwise stated. MPM, Malignant pleural mesothelioma; $M C D$, malignant chest disease other than malignant pleural mesothelioma; $B C D$, benign chest disease; NSCLC, non-small cell lung cancer. *Benign chest disease comprised the following diagnoses: pleural empyema $(\mathrm{n}=10)$, pneumothorax $(\mathrm{n}=3)$, and miscellaneous $(\mathrm{n}=10)$. $\dagger$ Patients with benign chest disease were significantly younger than patients in the 2 other groups $(P<.001)$; there was no significant difference in age between patients with malignant pleural mesothelioma and malignant chest disease other than malignant pleural mesothelioma $(P=.42)$. $¥$ There was no significant difference in sex distribution between the study group (malignant pleural mesothelioma) and the control groups $(P=.32)$. § There was no significant difference in smoking history between the study group (malignant pleural mesothelioma) and the control groups $(P=.11)$. $\|$ Miscellaneous malignant chest diseases were as follows: thoracic metastatic disease from extrathoracic primary $(n=20)$, carcinoid tumors $(n=5)$, small cell lung cancer $(n=4)$, mesenchymal tumors $(\mathrm{n}=4)$, thoracic non-Hodgkin lymphoma $(\mathrm{n}=2)$, thymus carcinoma $(\mathrm{n}=1)$.

the Fisher Exact test, or the Fisher-Halton-Freeman test, depending on the percentage of expected frequencies below 5 . Because of outliers, the Spearman rank correlation was used to correlate serum ILK with age. To compare the 3 patient groups with respect to serum ILK, a 1-way analysis of variance with Welch correction and the Games-Howell procedure as post hoc test were used because of heterogeneous variances. To test the relationships of asbestos exposure, histologic subtypes of MPM, combined stage of
MPM, disease progression of MPM, and survival status of MPM with serum ILK concentration, $t$ tests were performed. Additionally, a receiver operating characteristic analysis was performed to obtain a cutoff value for the distinction between MPM and other diseases. Sensitivity, specificity, negative predictive value, and positive predictive value were calculated with their $95 \%$ confidence intervals. Cox regression was used to assess the effect of combined stage of MPM, asbestos exposure, histologic subtype of MPM, and ILK on survival time. Linear and nonlinear regressions were performed to test the influences of lactate dehydrogenase, creatine kinase, alanine aminotransferase, and aspartate aminotransferase on serum ILK. An intraclass correlation coefficient was calculated to assess the quality of the measurements obtained for standard curves.

\section{RESULTS}

The median serum ILK concentration in patients with MPM was $8.89 \mathrm{ng} / \mathrm{mL}$, significantly higher than in patients with MCD $(0.66 \mathrm{ng} / \mathrm{mL})$ or in those with $\mathrm{BCD}(0.78 \mathrm{ng} / \mathrm{mL}$, $P<.001)$; however, the median serum ILK concentrations were statistically not different between patients with MCD and BCD (Table 2). There was no correlation of serum ILK with patient age $(\rho=-0.03, P=.72)$. Furthermore, there was no relevant correlation of serum ILK with cell lysis parameters creatine kinase, lactate dehydrogenase, aspartate aminotransferase, and alanine aminotransferase $\left(R^{2}<0.1\right.$ always, data not shown). The distribution of serum ILK concentrations in MPM was highly variable (Figure 1). In the receiver operating characteristic analysis, a cutoff value of serum ILK concentration greater than 2.48 $\mathrm{ng} / \mathrm{mL}$ was found to have a diagnostic sensitivity of $80 \%$, a specificity of $95 \%$, a positive predictive value of $85.7 \%$, a negative predictive value of $92.7 \%$, and an overall accuracy of $91 \%$ for the distinction between MPM and MCD or BCD (area under the curve $89.1 \%, 95 \%$ confidence interval $82 \%-96.1 \%$; Figure 2, Tables 3 and 4).

In univariate analysis, the serum ILK concentration in MPM was independent of asbestos exposure, histologic subtype, combined clinical stage, disease progression, and survival (Table 5). To compensate for multiple interactions between serum ILK concentration and the wellestablished MPM prognostic factors of histological subtype, asbestos exposure, and combined stage, a multivariate model for the assessment of the effect of serum ILK concentration on MPM survival was constructed. In this model, only combined stage emerged as a statistically significant factor for MPM survival, with longer survival in patients with stage I and II MPM $(P=.002)$. In the multivariate

TABLE 2. Serum integrin-linked kinase determination: Raw values (ng/mL) in study (malignant pleural mesothelioma) and control groups

\begin{tabular}{lccccc}
\hline & Median & IQR & Minimum & Maximum & Mean \pm SD \\
MPM & 8.89 & 10.5 & 0 & 49.96 & $10.79 \pm 9.89$ \\
MCD & 0.66 & 1.11 & 0 & 6.3 & $0.84 \pm 1.07$ \\
BCD & 0.78 & 1.46 & 0 & 2.7 & $0.94 *$ \\
\hline
\end{tabular}

$I Q R$, Interquartile range; $M P M$, malignant pleural mesothelioma; $M C D$, malignant chest disease other than malignant pleural mesothelioma; $B C D$, benign chest disease. $*$ Malignant pleural mesothelioma versus malignant chest disease other than malignant pleural mesothelioma and benign chest disease. $\dagger$ Malignant chest disease other than malignant pleural mesothelioma versus benign chest disease. †There was no significant difference in serum integrin-linked kinase concentration between squamous and nonsquamous nonsmall cell lung cancer $(P=.95)$. 


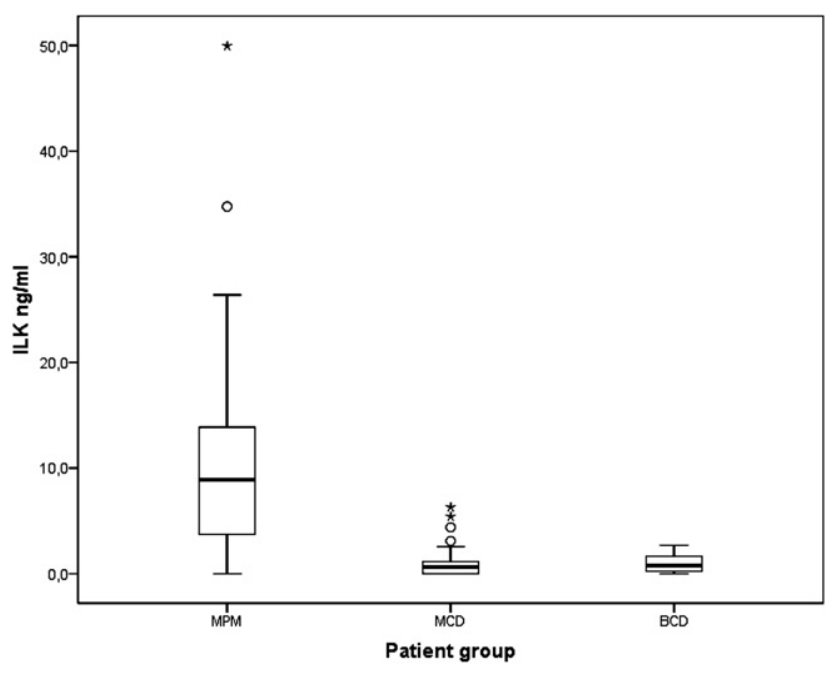

FIGURE 1. Box plot of serum integrin-linked kinase (ILK) concentrations. $M P M$, Malignant pleural mesothelioma, $M C D$, malignant chest disease other than malignant pleural mesothelioma, $B C D$, benign chest disease.

model, there was no statistically significant effect of serum ILK concentration on MPM survival (Table 6).

\section{DISCUSSION}

In this study, we have shown that ILK can be detected in the serum of patients with MPM, that the concentration of serum ILK is significantly higher in patients with MPM than in those with MCD and BCD, that these concentration differences are strong enough to distinguish with a sensitivity of $80 \%$ and a specificity of $95 \%$ between MPM and MCD or BCD, and that the serum ILK concentration does not predict the prognosis of patients with MPM.

The mechanism of ILK release into the bloodstream is not clear. Two main mechanisms could theoretically be re-

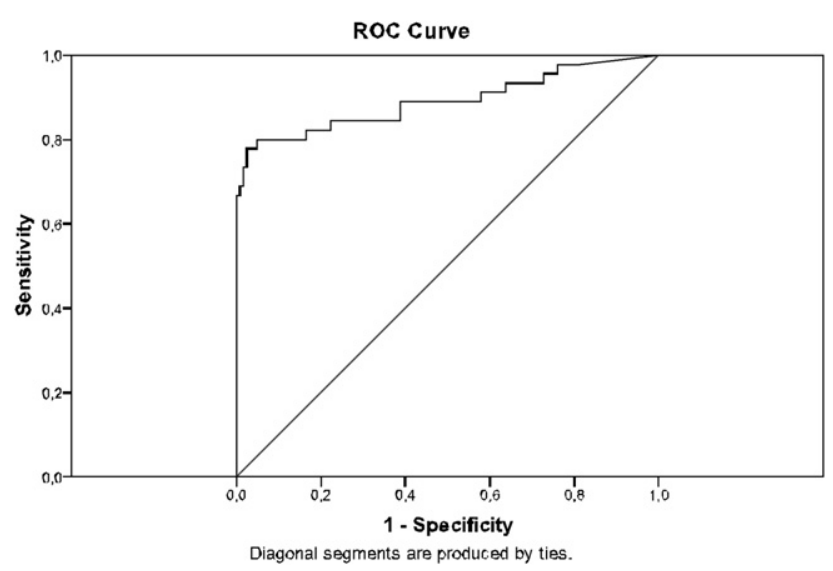

FIGURE 2. Receiver operating characteristic $(R O C)$ curve for serum integrin-linked kinase in malignant pleural mesothelioma versus other malignant chest disease or benign chest disease. Area under the curve is $89.1 \%(95 \%$ confidence interval, $82 \%-96.1 \%)$ at a cutoff value of 2.48 $\mathrm{ng} / \mathrm{mL}$.
TABLE 3. Serum integrin-linked kinase determination: Diagnostic test result for malignant pleural mesothelioma versus presence of disease

\begin{tabular}{lccr}
\hline & \multicolumn{3}{c}{ Disease presence } \\
\cline { 2 - 4 } Test result & Positive & Negative & Total \\
\hline Positive & 36 & 6 & 42 \\
Negative & 9 & 115 & 124 \\
Total & 45 & 121 & 166 \\
\hline
\end{tabular}

Values represent numbers of patients. Threshold value of serum integrin-linked kinase level was $2.48 \mathrm{ng} / \mathrm{mL}$.

sponsible for the release of ILK into the bloodstream: (1) increased cell lysis, which is unlikely in our case because at least in 120 out of 166 samples there was no relevant correlation between serum ILK concentration and cell lysis parameters, and (2) active secretion, which is also unlikely, because there is no active secretion of members of the integrin family. ${ }^{15}$ Many cell types, however, including human MPM cells, are able to release microvesicles of endosomal origin, called exosomes, that present the inner side of the cell membrane on the outside, thus allowing detection of many membrane-bound cytoplasmic proteins (including members of the integrin family) on their surface. ${ }^{16,17}$ To test the hypothesis of an exosomal origin of serum ILK, exosome isolation should be done in future studies.

The novel observation of an increased serum ILK concentration in patients with MPM relative to those with MCD or BCD fits well with the previously described role of ILK in MPM. ${ }^{11-13}$ The observation of lower serum ILK concentration in MCD, however, is somewhat contradictory to previously published evidence of a comparably high degree of ILK expression in tissue specimens of lung adenocarcinoma $(79 \%) .{ }^{18}$ This is particularly surprising, because the proportion of adenocarcinoma (labeled here as nonsquamous non-small cell lung cancer) was, at $40 \%$ of the MCD group, high enough to detect possible differences in serum ILK concentration. On the other hand, the MCD group contained a higher proportion of early-stage cases than did the MPM group. It therefore cannot be excluded that extensive pleural carcinomatosis of adenocarcinoma (from the lung or metastatic) would yield serum ILK concentrations as high as those of epitheloid MPM. Future studies comparing the serum ILK concentration of all histologic subgroups of MPM with stage-matched

TABLE 4. Serum integrin-linked kinase determination: Diagnostic validity for malignant pleural mesothelioma

\begin{tabular}{llc}
\hline & $\%$ & $\mathbf{9 5} \%$ Confidence interval \\
\hline Sensitivity & 80 & $66.2-89.1$ \\
Specificity & 95 & $89.6-97.7$ \\
Positive predictive value & 85.7 & $72.2-93.3$ \\
Negative predictive value & 92.7 & $86.8-96.1$ \\
Accuracy & 91 & $85.6-94.4$ \\
\hline
\end{tabular}

Threshold value of serum integrin-linked kinase level was $2.48 \mathrm{ng} / \mathrm{mL}$. 
TABLE 5. Correlation of serum integrin-linked kinase concentration with clinical parameters of malignant pleural mesothelioma: Univariate analysis

\begin{tabular}{lcc}
\hline & $\begin{array}{c}\text { Serum concentration } \\
(\mathbf{n g} / \mathbf{m L})\end{array}$ & P value \\
\hline Asbestos exposure & $11 \pm 8.93$ & .8 \\
$\quad$ No & $10.71 \pm 10.35$ & \\
$\quad$ Yes & $11.07 \pm 10.58$ & .8 \\
Histologic subtype & $10.23 \pm 8.66$ & \\
$\quad$ Epitheloid & & \\
$\quad$ Other & $8.75 \pm 7.02$ & .4 \\
Combined stage & $12.15 \pm 11.34$ & \\
$\quad$ Stages I and II & \\
$\quad$ Stages III and IV & $9.15 \pm 9.55$ & \\
Disease progression & $11.14 \pm 10.05$ & .4 \\
$\quad$ No & & \\
$\quad$ Yes & & \\
Survival status & $9.24 \pm 8.56$ & \\
$\quad$ Survived & $11.73 \pm 10.66$ & \\
$\quad$ Died & & \\
\hline Concentration values are mean \pm SD. &
\end{tabular}

histologic subgroups of MCD will answer these open questions.

The diagnostic validity of serum ILK, with its sensitivity of $80 \%$ and its specificity of $95 \%$ in the discrimination between MPM and MCD or BCD, compares favorably with the diagnostic validity of soluble mesothelin-related peptides (SMRPs), osteopontin, and megakaryocyte potentiation factor, the 3 currently most investigated biomarkers of MPM. SMRPs are highly increased in the serum of patients with MPM. ${ }^{19}$ The sensitivity of serum SMRP in differentiating mesothelioma from benign lesions is $73 \%$ to $80 \%$, with a specificity of $82.6 \%$ to $95 \% .^{20,21}$ In a recent prospective study in 538 subjects with occupational exposure to asbestos, however, a low specificity and a high number of false-positive values of serum SMRP were seen. ${ }^{22}$ In addition, increased levels of serum SMRP can only be found in the epitheloid but not in the sarcomatoid subtype of MPM, ${ }^{19}$ unlike ILK, which can be found in all MPM subtypes. ${ }^{11,12}$ Serum osteopontin levels discriminate between MPM and asbestos-exposed individuals with a sensitivity of $47 \%$ to $77.6 \%$ and a specificity of $85.5 \%$ to $95 \% .{ }^{21,23}$ Serum osteopontin is unable,

TABLE 6. Correlation of serum integrin-linked kinase concentration with clinical parameters of malignant pleural mesothelioma: Multivariate analysis

\begin{tabular}{lcc}
\hline & Hazard ratio for survival & $\boldsymbol{P}$ value \\
\hline Serum integrin-linked kinase & 1.006 & .8 \\
$\quad$ concentration & 2.246 & .1 \\
Asbestos exposure & 1.974 & .1 \\
Histologic subtype & 0.205 & .002 \\
Combined stage* & & \\
*Patients with stage I and II malignant pleural mesothelioma lived longer than pa- \\
tients with stage III and IV mesothelioma $(P=.002)$.
\end{tabular}

however, to distinguish between MPM and pleural metastatic carcinoma. ${ }^{24}$ Serum megakaryocyte potentiation factor discriminates with a sensitivity of $74.1 \%$ and a specificity of $90.4 \%$ between patients with MPM, patients with lung cancer, healthy asbestos-exposed subjects, and healthy adults ${ }^{25}$ and with a sensitivity of $34 \%$ and a specificity of $95 \%$ between patients with MPM, healthy control subjects, and patients with benign asbestos-related disease. ${ }^{21}$ In summary, serum ILK seems to have a higher sensitivity and specificity in discriminating MPM from both MCD and BCD conditions than either osteopontin or megakaryocyte potentiation factor.

The finding that the serum concentration of ILK was prognostic neither for disease progression nor for overall survival parallels our previous observation that ILK expression in MPM samples failed to predict prognosis. ${ }^{12}$ Because the variance in serum ILK concentration values was so pronounced, however, the statistical power of our analysis regarding the prognostic value of serum ILK was low and thus warrants repetition of the experiments in a much bigger study population before definitive conclusions can be drawn. In addition, because of the relatively small sample size, the lack of statistical difference in serum ILK concentrations between early and late stage MPM must also be interpreted with caution.

Future investigations will need to answer the open questions. First, it is necessary to ascertain the tissue source of serum ILK in benign and malignant conditions. In addition to serum ILK determination, biopsy of the implicated tissue or disease process is warranted. Furthermore, the normal value of serum ILK is unknown. To determine a good reference value, a systematic investigation of serum ILK levels among healthy subjects and patients with all types of benign and malignant disease conditions is necessary. Finally, to evaluate the true prognostic value of serum ILK level in MPM, it should be determined serially in patients with MPM - at diagnosis, after therapy, during follow-up — and values should be analyzed with respect to quantitative measures of tumor burden (eg, by computed tomographic volumetric analysis) or of tumor metabolic activity (eg, by positron emission tomographic scan).

\section{CONCLUSIONS}

Our study confirms the presence of ILK in the serum of patients with MPM and shows for the first time that it is significantly higher in these patients than in patients with other chest diseases. Overall, this study underlines the specific association of ILK with MPM and points to several ways in which this association might be practically exploited in the future.

We thank Barbara Dekan, technical assistant at the Cardiac Surgery Research Laboratory, Medical University of Vienna, Vienna, Austria, for her contributions to the establishment of our 
integrin-linked kinase-specific enzyme-linked immunosorbent assay. We are grateful to Michael Weber, $\mathrm{MSc}, \mathrm{PhD}$, for performing a thorough statistical analysis.

\section{References}

1. Mujoomdar AA, Tilleman TR, Richards WG, Bueno R, Sugarbaker DJ. Prevalence of in vitro chemotherapeutic drug resistance in primary malignant pleural mesothelioma: result in a cohort of 203 resection specimens. J Thorac Cardiovasc Surg. 2010;140(2):352-5.

2. Scherpereel A, Astoul P, Baas P, Berghmans T, Clayson H, de Vuyst P, et al. Guidelines of the European Respiratory Society and the European Society of Thoracic Surgeons for the management of malignant pleural mesothelioma. Eur Respir J. 2010;35:479-95.

3. Yan TD, Boyer M, Tin MM, Wong D, Kennedy C, McLean J, et al. Extrapleural pneumonectomy for malignant pleural mesothelioma: outcomes of treatment and prognostic factors. J Thorac Cardiovasc Surg. 2009;138:619-24.

4. Vogelzang NJ. Chemotherapy for malignant pleural mesothelioma. Lancet. 2008;371:1640-2

5. McAleer MF, Tsao AS, Liao Z. Radiotherapy in malignant pleural mesothelioma. Int J Radiat Oncol Biol Phys. 2009;75:326-37.

6. Yang H, Testa JR, Carbone M. Mesothelioma epidemiology, carcinogenesis, and pathogenesis. Curr Treat Options Oncol. 2008;9:147-57.

7. Hannigan GE, Leung-Hagesteijn C, Fitz-Gibbon L, Coppolino MG, Radeva G, Filmus J, et al. Regulation of cell adhesion and anchorage-dependent growth by a new beta 1-integrin-linked protein kinase. Nature. 1996;379:91-6.

8. Tan C, Mui A, Dedhar S. Integrin-linked kinase regulates inducible nitric oxide synthase and cyclooxygenase- 2 expression in an NF-kappa B-dependent manner. J Biol Chem. 2002;277:3109-16.

9. Hannigan G, Troussard AA, Dedhar S. Integrin-linked kinase: a cancer therapeutic target unique among its ILK. Nat Rev Cancer. 2005;5:51-63.

10. Yoganathan N, Yee A, Zhang Z, Leung D, Yan J, Fazli L, et al. Integrin-linked kinase, a promising cancer therapeutic target: biochemical and biological properties. Pharmacol Ther. 2002;93:233-42.

11. Watzka SB, Setinek U, Huber M, Cantonati H, Lax F, Watson S, et al. Reactivity of integrin-linked kinase in human mesothelial cell proliferation. Interact Cardiovasc Thorac Surg. 2008;7:107-10.

12. Watzka SB, Setinek U, Stubenberger EB, Tötsch M, Dekan G, Marcher M, et al. Integrin-linked kinase, phosphorylated AKT and the prognosis of malignant pleural mesothelioma. Eur J Cardiothorac Surg. 2011;39:180-4.
13. An Z, Dobra K, Lock JG, Strömblad S, Hjerpe A, Zhang H. Kindlin-2 is expressed in malignant mesothelioma and is required for tumor cell adhesion and migration. Int J Cancer. 2010;127:1999-2008.

14. Ahmed N, Oliva K, Rice GE, Quinn MA. Cell-free 59 kDa immunoreactive integrin-linked kinase: a novel marker for ovarian carcinoma. Clin Cancer Res. 2004;10:2415-20.

15. Cox D, Brennan M, Moran N. Integrins as therapeutic targets: lessons and opportunities. Nat Rev Drug Discov. 2010;9:804-20.

16. Théry C, Zitvogel L, Amigorena S. Exosomes: composition, biogenesis and function. Nat Rev Immunol. 2002;2:569-79.

17. Hegmans JP, Bard MP, Hemmes A, Luider TM, Kleijmeer MJ, Prins JB, et al Proteomic analysis of exosomes secreted by human mesothelioma cells. Am J Pathol. 2004;164:1807-15.

18. Watzka SB, Rauscher-Pötsch I, Stubenberger E, Getman V, Setinek U, Tötsch M et al. Immunoreactivity of integrin-linked kinase in primary non-small-cell lung cancer and survival after curative resection. Eur J Cardiothorac Surg. 2010;38: 254-9.

19. Robinson BW, Creaney J, Lake R, Nowak A, Musk AW, de Klerk N, et al. Mesothelin-family proteins and diagnosis of mesothelioma. Lancet. 2003;362: 1612-6.

20. Scherpereel A, Grigoriu B, Conti M, Gey T, Grégoire M, Copin MC, et al. Soluble mesothelin-related peptides in the diagnosis of malignant pleural mesothelioma. Am J Respir Crit Care Med. 2006;173:1155-60.

21. Creaney J, Yeoman D, Demelker Y, Segal A, Musk AW, Skates SJ, et al. Comparison of osteopontin, megakaryocyte potentiating factor, and mesothelin proteins as markers in the serum of patients with malignant mesothelioma. $J$ Thorac Oncol. 2008;3:851-7.

22. Park EK, Sandrini A, Yates DH, Creaney J, Robinson BW, Thomas PS, et al. Soluble mesothelin-related protein in an asbestos-exposed population: the dust diseases board cohort study. Am J Respir Crit Care Med. 2008;178:832-7.

23. Pass HI, Lott D, Lonardo F, Harbut M, Liu Z, Tang N, et al. Asbestos exposure pleural mesothelioma, and serum osteopontin levels. N Engl J Med. 2005;353: 1564-73.

24. Grigoriu BD, Scherpereel A, Devos P, Chahine B, Letourneux M, Lebailly P, et al. Utility of osteopontin and serum mesothelin in malignant pleural mesothelioma diagnosis and prognosis assessment. Clin Cancer Res. 2007;13: 2928-35.

25. Iwahori K, Osaki T, Serada S, Fujimoto M, Suzuki H, Kishi Y, et al. Megakaryocyte potentiating factor as a tumor marker of malignant pleural mesothelioma: evaluation in comparison with mesothelin. Lung Cancer. 2008;62:45-54. 